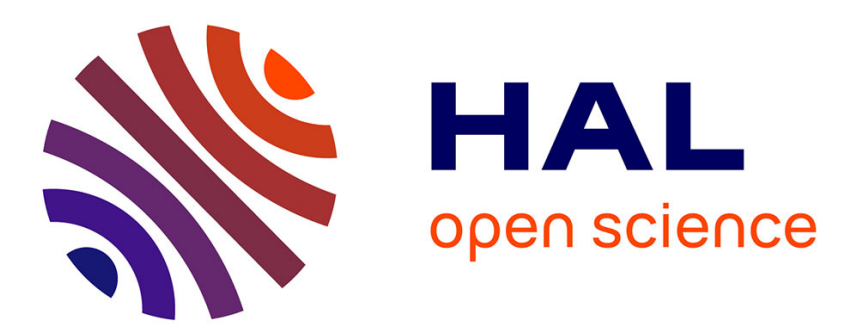

\title{
Spectrophotometric investigation of nickel(II) chloro complexes in alcoholic solutions
}

Mustayeen A Khan, Denis Cronier, Gilles M Bouet, Francois Vierling

\section{To cite this version:}

Mustayeen A Khan, Denis Cronier, Gilles M Bouet, Francois Vierling. Spectrophotometric investigation of nickel(II) chloro complexes in alcoholic solutions. Transition Metal Chemistry, 1995, 20, pp.369-371. 10.1007/BF00139132 . hal-03187756

\section{HAL Id: hal-03187756 \\ https://univ-angers.hal.science/hal-03187756}

Submitted on 8 Apr 2021

HAL is a multi-disciplinary open access archive for the deposit and dissemination of scientific research documents, whether they are published or not. The documents may come from teaching and research institutions in France or abroad, or from public or private research centers.
L'archive ouverte pluridisciplinaire HAL, est destinée au dépôt et à la diffusion de documents scientifiques de niveau recherche, publiés ou non, émanant des établissements d'enseignement et de recherche français ou étrangers, des laboratoires publics ou privés. 


\title{
Spectrophotometric investigation of nickel(II) chloro complexes in alcoholic solutions
}

\author{
Mustayeen A. Khan*, Denis Cronier and Gilles M. Bouet \\ Laboratoire de Chimie de Coordination, Université d'Angers, Faculté de Pharmacie, 16 Boulevard Daviers, F-49100 \\ Angers, France
}

\section{François Vierling}

Laboratoire de Chimie physique, Unité Associée au CNRS $N^{\circ}$ 405, EHICS, Université Louis Pasteur, 1 Rue Blaise Pascal, F-67000 Strasbourg, France

\begin{abstract}
Summary
A spectrophotometric study of $\mathrm{Ni}^{\mathrm{II}}$ chloro complexes in the u.v.-vis. region was carried out at $25^{\circ} \mathrm{C}$ and constant ionic strength of $1 \mathrm{~mol} \mathrm{dm}^{-3}$. A matrix rank treatment method was used to identify two successive mononuclear complexes, $\mathrm{NiCl}^{+}$and $\mathrm{NiCl}_{2}$, in the three alcohols studied viz. $\mathrm{MeOH}, \mathrm{EtOH}$ and $i$-PrOH. The best values for the apparent overall stability constants, $\beta_{j}$, were calculated using a program based on the least-squares method. The $\log \beta_{1}$ and $\log \beta_{2}$ values in $\mathrm{MeOH}, \mathrm{EtOH}$ and $i-\mathrm{PrOH}$ are 1.3 and $1.2,1.7$ and 1.8 , and 1.9 and 2.2 , respectively. The stability increases directly with the mol. wt. of the solvent, or decreases as a linear function of the permittivity of the pure solvent. The electronic spectra and the formation curves of the two complexes in $\mathrm{MeOH}$ solutions were calculated.
\end{abstract}

\section{Introduction}

Chloro complexes of nickel(II) have been studied in the solid state, and in aqueous and organic solutions. In the solid state, some of the important studies confer a tetrahedral structure upon the nickel(II) complexes ${ }^{(1-4)}$. Cotton and Wilkinson ${ }^{(5)}$ believe that the structure of $\mathrm{CoCl}_{2}$ and $\mathrm{NiCl}_{2}$ can be either octahedral or tetrahedral but whenever the coordination number exceeds 2 the complex is tetrahedral.

In aqueous solutions, the absence of $\mathrm{NiCl}_{4}^{2-}$ has been reported by Gill Nyholm ${ }^{(1)}$ and Blake ${ }^{(6)}$. However, its formation has been postulated by Scarrow and Griffiths ${ }^{(7)}$, based upon absorption maxima at 600,650 and $700 \mathrm{~nm}$. Wendling et al.$^{(8)}$ have shown the presence of two chloro complexes of nickel in aqueous perchloric acid which they described as inner or outer complexes; for the latter, the formation constant was calculated as 0.3 . They have also underlined the absence of the tetrachloro complex of nickel. Recently, Licheri et al ${ }^{(9)}$ have confirmed the presence of the monochloro complex and the probable existence of a higher coordinated complex.

Gutman and co-workers ${ }^{(10-13)}$ studied the chloro complexes of transition metals, $\mathrm{Co}^{2+}, \mathrm{Ni}^{2+}$ and $\mathrm{Cu}^{2+}$, in different organic solvents such as trimethylphosphate, $\mathrm{CH}_{3} \mathrm{CN}, \mathrm{DMF}$ and propylene carbonate. In these solutions, they have indicated the existence of several successive, mono to tetra, chloro complexes. They have also postulated that in DMF the dichloro complex autodissociates into mono- and trichloro complexes, but in all these studies no stability constants were calculated.

\footnotetext{
* Author to whom all correspondence should be directed.
}

Ishiguro et al. ${ }^{(14)}$ have also reported the presence of four mononuclear successive complexes in DMF.

We have previously studied the chloro complexes of copper(II) in aqueous solutions $\mathrm{s}^{(15)}$, and in various organic solvents, especially alcohols $\mathrm{s}^{(16-20)}$, and have recently published the results of cobalt(II) complexes in $\mathrm{EtOH}$ and $i$-PrOH ${ }^{(21)}$. In this paper, we report the results of nickel(II) chloride complexes in $\mathrm{MeOH}$, EtOH and $i$-PrOH. A multiwavelength spectrophotometric investigation technique was used to calculate the apparent overall stability constants, $\beta_{j}$, for the equilibrium:

$$
\mathrm{Ni}^{2+}+j \mathrm{Cl}^{-} \rightleftharpoons \mathrm{NiCl}_{j}^{(j-2)-}
$$

where $\beta_{j}=\left[\mathrm{NiCl}_{j}^{(j-2)-}\right] /\left[\mathrm{Ni}^{2+}\right]\left[\mathrm{Cl}^{-}\right]^{j}$. This quantitative approach allowed us to calculate the electronic spectra of the species identified and to compare their stabilities and spectra in different alcohols. This project will eventually be followed by a comparative study of the evolution of their thermodynamic and spectroscopic properties, not only in the solvent alcohols but also in the periodic table from cobalt to copper in the first transition series.

\section{Experimental}

$\mathrm{MeOH}, \mathrm{EtOH}$ and $i-\mathrm{PrOH}$ pro analysi's (Merck) were used without further treatment. Anhydrous $\mathrm{LiCl}, \mathrm{LiClO}_{4}$ and $\mathrm{Ni}\left(\mathrm{ClO}_{4}\right)_{2} \cdot 6 \mathrm{H}_{2} \mathrm{O}$ (Fluka p.a.) were used to prepare stock solutions; subsequent solutions under investigation were obtained by dilution. The absorption variations were recorded on a Shimadzu UV 2101 PC spectrophotometer at $25^{\circ} \mathrm{C}$ and the ionic strength of solutions was maintained constant, fixed at $1 \mathrm{~mol} \mathrm{dm}^{-3}$, with the help of the supporting electrolyte $\mathrm{LiClO}_{4}$. The fundamental reason for choosing this ionic strength was in order to compare the results of other chloro complexes under identical conditions. The analytical concentration of the metal was fixed at $0.01 \mathrm{~mol} \mathrm{dm}^{-3}$, and that of the ligand varied from 0.01 to $1.0 \mathrm{~mol} \mathrm{dm}^{-3}$. Under the experimental conditions only the formation of the mononuclear complexes was envisaged. The numerical calculations were done on the IBM 3090 computer of the Université Louis Pasteur, Strasbourg.

\section{Results and discussion}

As the results are not very different with respect to the alcohol, we present in detail those of nickel(II) chlorides in $\mathrm{MeOH}$, while for those concerning EtOH and $i$-PrOH only the final calculations will be given. Figure 1 shows the variation of experimental spectra of nickel(II) chloride solutions in $\mathrm{MeOH}$. For the solution of nickel in the absence of chloride ions there is an absorption band in the 

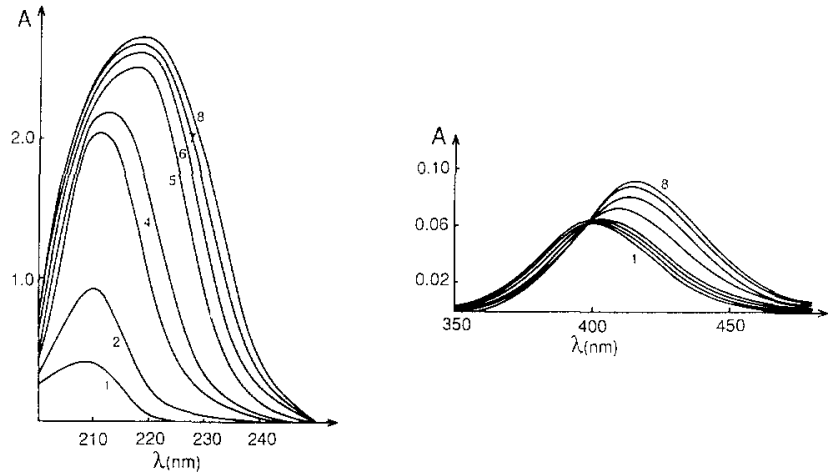

Fig. 1. Absorption spectra of nickel(II)- $\mathrm{Li}^{+}\left(\mathrm{Cl}^{-}, \mathrm{ClO}_{4}^{-}\right) 1 \mathrm{M}$ solutions in $\mathrm{MeOH}:\left[\mathrm{Ni}^{\mathrm{II}}\right]=0.01 \mathrm{~mol} \mathrm{dm}{ }^{-3}, 1_{\text {cuve }}=1 \mathrm{~cm} . ;\left[\mathrm{Cl}^{-}\right]$ $\left(\mathrm{mol} \mathrm{dm}^{-3}\right): 1,0 ; 2,0.01 ; 3,0.05 ; 4,0.1 ; 5,0.3 ; 6,0.6 ; 7,0.8 ; 8,1.0$.

u.v. region at $210 \mathrm{~nm}$ and another in the vis. region at $400 \mathrm{~nm}$. These two absorption bands undergo a hyperchromic and a bathochromic shift upon addition of chloride ions and are stabilized for a concentration of chloride ions of $1 \mathrm{~mol} \mathrm{dm}^{-3}$, at 220 and $415 \mathrm{~nm}$. For solutions of higher concentrations an isosbestic point at $397 \mathrm{~nm}$ is observed.

In order to determine the minimum number of absorbing species present in the solution, a matrix rank treatment method, based on the work of Hugus and El Awady ${ }^{(22)}$, was used. This requires a set of $N \times L$ data of absorption values, where $N$ is the number of solutions and $L$ the number of wavelengths, and the rank of the matrice thus formed is equal to the minimum number of absorbing species present in solution. The result of this analysis in all the three alcohols indicated the presence of two complexes for which the overall stability constants were calculated using a laboratory program based upon a least-squares method. The details of these calculations were given in our earlier publications ${ }^{(23,24)}$

Working under the assumption that only successive mononuclear complexes are formed, the two species are formulated as $\mathrm{NiCl}^{+}$and $\mathrm{NiCl}_{2}$ and the best values for the stability constants are summarized in Table 1. For resolution by the least-squares method, the function to be minimized can be assimilated to a paraboloid of $n$ dimensions. The calculations determine the zone of dispersion of parameters in which the probability of finding them is $95 \%{ }^{(25)}$, i.e. the zone of the sum minimum, $S_{\mathrm{m}}$, surrounded by the standard deviation: $S_{\mathrm{m}} \pm 4 \sigma^{2}$. The values of stability constants are therefore given with an uncertainty of $c a$. $8 \%$ : in $\mathrm{MeOH}, \beta_{1}=20.0 \pm 1.6, \beta_{2}=14.6 \pm 1.2$; in $\mathrm{EtOH}$, $\beta_{1}=48.0 \pm 3.8, \quad \beta_{2}=64.0 \pm 5.0 ;$ and in $i-\mathrm{PrOH}$,

Table 1. Overall stability constants of $\mathrm{NiCl}^{+}$and $\mathrm{NiCl}_{2}$ and standard deviations, $\sigma$, for the three alcohols

\begin{tabular}{llll}
\hline & $\begin{array}{l}\text { Solvent } \\
\text { MeOH }\end{array}$ & $\begin{array}{l}\text { EtOH } \\
46\end{array}$ & $\begin{array}{l}\text { i-PrOH } \\
\text { Mol. wt. }\end{array}$ \\
32 & 24 & 19.5 \\
Permittivity, $\varepsilon_{\mathrm{r}}$ & 33 & 48 & 88 \\
\hline$\beta_{1}$ & 20 & $(1.7)$ & $(1.9)$ \\
$\left(\log \beta_{1}\right)$ & $(1.3)$ & 64 & 176 \\
$\beta_{2}$ & 14.6 & $(1.8)$ & $(2.2)$ \\
$\left(\log \beta_{2}\right)$ & $(1.2)$ & 0.092 & 0.093 \\
$\sigma$ & 0.066 & & \\
\hline
\end{tabular}

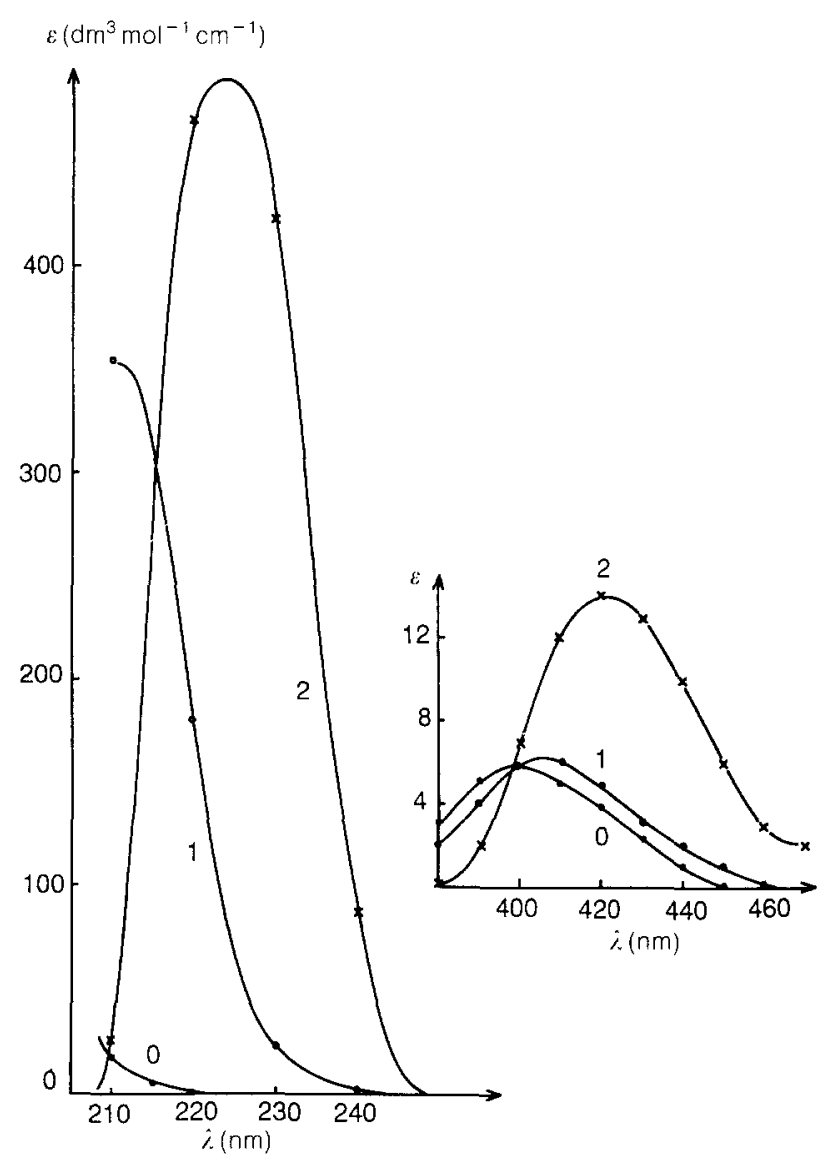

Fig. 2. Calculated electronic spectra for the nickel(II) chloro complexes in $\mathrm{MeOH} .0, \mathrm{Ni}^{2+} ; 1, \mathrm{NiCl}^{+} ; 2, \mathrm{NiCl}_{2}$.

$\beta_{1}=88.0 \pm 7.0, \beta_{2}=176 \pm 14$.

The standard deviation, $\sigma$, describes the relative agreement between experimental and calculated absorption values and is 0.066, 0.092 and 0.093 in $\mathrm{MeOH}, \mathrm{EtOH}$ and $i$-PrOH, respectively. This means that these stability constants permit us to recalculate the absorptions to within $6.6,9.2$ and $9.3 \%$ of the experimental values in the respective alcohols.

These stability constants were used to calculate the specific extinction coefficients, and the electronic spectra of the species in $\mathrm{MeOH}$ is represented in Figure 2. The nickel monochloro complex has a maximum at $c a$. $210 \mathrm{~nm}$, which could not be ascertained accurately, and another band of weak intensity at $410 \mathrm{~nm}\left(\varepsilon_{\max } c a\right.$. $6.5 \mathrm{dm}^{3} \mathrm{~mol}^{-1} \mathrm{~cm}^{-1}$ ) which in EtOH and $i-\mathrm{PrOH}$ is situated at $420 \mathrm{~nm}$. The dichloro complex has its characteristic absorption band at $225 \mathrm{~nm}\left(\varepsilon_{\max } \quad c a\right.$. $480 \mathrm{dm}^{3} \mathrm{~mol}^{-1} \mathrm{~cm}^{-1}$ ) and, in the vis., it absorbs at $425 \mathrm{~nm}\left(\varepsilon_{\max } c a .14 \mathrm{dm}^{3} \mathrm{~mol}^{-1} \mathrm{~cm}^{-1}\right)$. For this complex its characteristic u.v. absorption maximum undergoes a bathochromic shift to $230 \mathrm{~nm}$ in $\mathrm{EtOH}$ and $i-\mathrm{PrOH}$, whereas the band in the vis. region is always found at $425 \mathrm{~nm}$ in all three alcohols. A comparison of Figures 1 and 2 shows that the recalculated isosbestic point at $398 \mathrm{~nm}$ is in very good agreement with the experimental point observed at $397 \mathrm{~nm}$. In EtOH and $i$-PrOH, experimental and calculated electronic spectra are also in good agreement.

Figure 3 represents the formation curves for the nickel(II) chloro complexes in $\mathrm{MeOH}$. Within the experimental zone the monochloro complex predominates and at free ligand concentration of $1 \mathrm{~mol} \mathrm{dm}^{-3},(\log c=0)$ the di- 


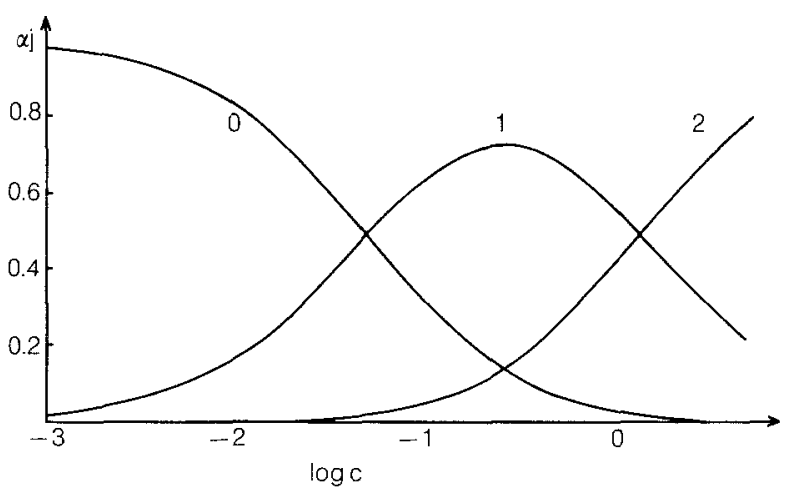

Fig. 3. Formation curves of nickel(II) chloro complexes in $\mathrm{MeOH}$. $\alpha$, degree of formation; $c$, free ligand concentration; 0 , $\mathrm{Ni}^{2+} ; 1, \mathrm{NiCl}^{+} ; 2, \mathrm{NiCl}_{2}$.

chloro complex is formed at ca. $40 \%$. There is, therefore the possibility of the formation of higher coordinated complexes, such as $\mathrm{NiCl}_{3}^{-}$and $\mathrm{NiCl}_{4}^{2-}$, in concentrated solutions.

We have therefore shown, under the experimental conditions, the presence of two complexes, which is in accordance with most of the earlier results. Some authors have postulated the presence of the tri- and tetrachloro complexes which are absent in our present work. We believe that in solution, highly coordinated complexes are formed exclusively in some dipolar aprotic organic solvents such as DMF, as reported by Gutman and co-workers ${ }^{(10-13)}$ and Ishiguro et al. ${ }^{(14)}$, and this also only in concentrated solutions.

The stability of the nickel chloro complexes increases directly with the number of carbons in the alcohols; the logarithm of the stability constants is a linear function of their mol. wt. This result was earlier reported by us with respect to copper(II) chloro complexes in alcoholic solutions $^{(18)}$. However, a much better linear fit is observed for a plot of $\log \beta_{j}$ versus the permittivity, $\varepsilon_{\mathrm{r}}$, of the pure
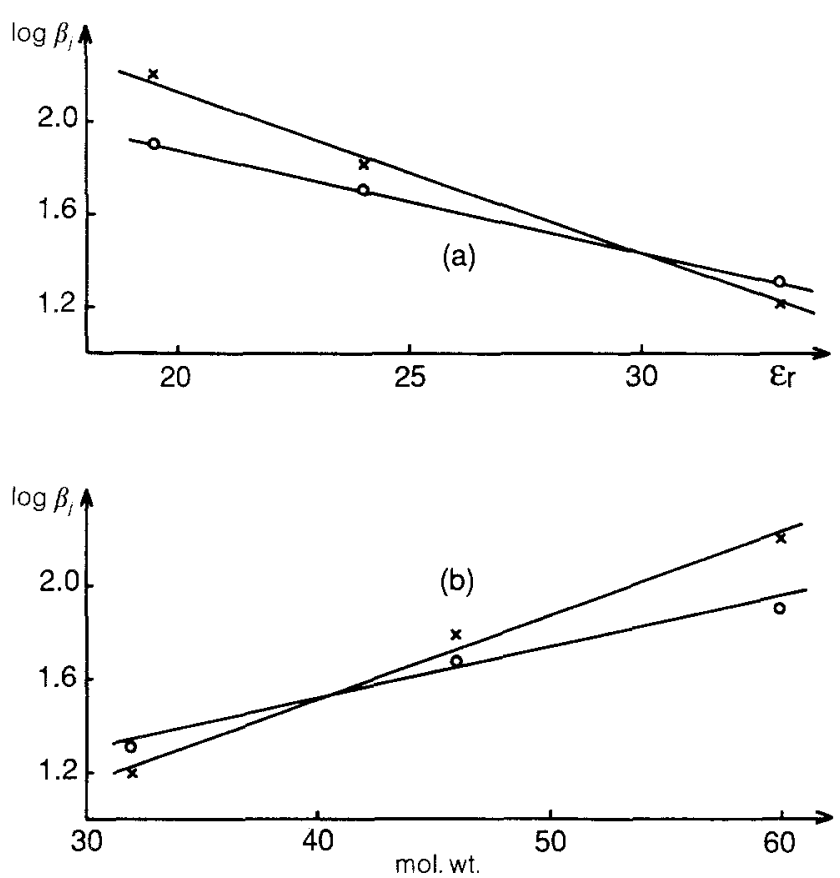

Fig. 4. Variation of the overall stability constants of the nickel(II) chloro complexes as a function of: (a) permittivity and (b) mol. wt. of the alcohols; $\mathrm{O}, \mathrm{NiCl}^{+} ; \times, \mathrm{NiCl}_{2}$. solvents. In this case, stability decreases regularly with increasing dissociating power of the solvent, and is probably due to the fact that a higher dissociating power promotes better hydrogen bonding and therefore hinders the substitution of the solvent molecule by the ligand in the inner coordination sphere of the metal. The variations of logarithms of constants as a function of mol. wt. and of permittivity of the solvents are shown in Figure 4; this is the first time such a relation has been established in this system.

\section{Conclusion}

Once the system of cobalt(II) chloro complexes is fully studied in the three alcohols it should be easy to determine whether the stability of the chloro complexes of the first transition metals in a given alcohol is a function of the atomic number of the central element, and, in this alcoholic medium, the Irving-Williams series is equally verified $^{(26)}$.

\section{References}

(1) N. S. Gill and R. S. Nyholm, J. Chem. Soc., 3997 (1959).

${ }^{(2)}$ F. A. Cotton and R. Francis, J. Am. Chem. Soc., 82, 2896 (1960).

${ }^{(3)}$ F. A. Cotton, O. D. Faut and D. M. L. Goodgame, J. Am. Chem. Soc., 83, 344 (1961).

${ }^{(4)}$ D. M. L. Goodgame, M. Goodgame and F. A. Cotton, J. Am. Chem. Soc., 83, 4161 (1961).

${ }^{(5)}$ F. A. Cotton and G. Wilkinson, Advanced Inorganic Chemistry, 4th Edit., Wiley: New York, 1978, p. 772.

${ }^{(6)}$ A. B. Blake and F. A. Cotton, Inorg. Chem., 1, 5 (1964).

(7) R. K. Scarrow and T. R. Griffiths, Chem. Comm., 425 (1967).

${ }^{(8)}$ E. Wendling, O. Benali-Baïtich and G. Yaker, Rev. Chim. Min., 8, 559 (1971).

${ }^{(9)}$ G. Licheri, G. Paschina, G. Piccaluga and G. Pinna, J. Chem. Phys., 79, 2168 (1983).

${ }^{(10)}$ M. Baaz, V. Gutmann, G. Hampel and J. R. Masaguer, Monatsh. Chem., 93, 1416 (1962).

(11) V. Gutmann, G. Hampel and J. R. Masaguer, Monatsh. Chem., 94, 822 (1963).

${ }^{(12)}$ H. Hubacek, B. Stancie and V. Gutmann, Monatsh. Chem., 94, 1118 (1963).

(13) V. Gutmann and H. Bardy, Monatsh. Chem., 99, 763 (1968).

${ }^{(14)}$ S. Ishiguro, K. Ozutsumi and H. Ohtaki, Bull. Chem. Soc. Jpn., 60, 531 (1987).

${ }^{(15)}$ M. A. Khan and M. J. Schwing-Weill, Inorg. Chem., 15, 2202 (1976).

${ }^{(16)}$ M. A. Khan, J. Meullemeestre, M. J. Schwing and F. Vierling, Inorg. Chem., 28, 3306 (1989).

${ }^{(17)}$ S. Chafaa, T. Douadi, M. A. Khan, J. Meullemeestre, M. J. Schwing and F. Vierling, Nouv. J. Chim., 15, 39 (1991).

${ }^{(18)}$ S. Dali, F. Benghanem, M. A. Khan, J. Meullemeestre and F. Vierling, Polyhedron, 10, 2529 (1991).

(19) E. Bentouhami, M. A. Khan, J. Meullemeestre and F. Vierling, Polyhedron, 11, 2179 (1992).

${ }^{(20)}$ F. Djabi, J. Meullemeestre, F. Vierling, G. Bouet and M. A. Khan, Bull. Soc. Chim. Fr., 131, 58 (1994).

${ }^{(21)}$ S. Lechat, M. A. Khan, G. Bouet and F. Vierling, Inorg. Chim. Acta, 211, 33 (1993).

${ }^{(22)}$ Z. Z. Hugus and A. A. El Awady, J. Phys. Chem., 75, 2954 (1971).

${ }^{(23)}$ M. Elleb, J. Meullemeestre, M. J. Schwing and F. Vierling, Inorg. Chem., 19, 2699 (1980).

${ }^{(24)}$ F. Vierling, M. J. Schwing and J. Meullemeestre, Spectra 2000, 79, 25 (1982).

(25) J. Bye, R. Hugel, G. Schorsch and R. Strosser, Bull. Soc. Chim. Fr., 1146 (1964).

${ }^{(26)}$ H. Irving and R. J. P. Williams, J. Chem. Soc., 3192 (1953).

(Received 19 September 1994)

TMC 3371 